\begin{tabular}{|ccc|}
\hline & ANNALES INSTITUTI SLAVICI \\
& UnIVERSITATIS DEBRECENIENSIS & \\
SLAVICA XLVII & 2018 & DEBRECEN \\
\hline
\end{tabular}

Ольга СЮч - Татьяна ЮдинА

\title{
КУЛЬТУРНАЯ ПОЛИТИКА РОССИИ И ВЕНГРИИ: СОВРЕМЕННЫЙ ДИСКУРС И НОВЫЕ СУБЪЕКТЫ
}

\author{
Cultural policy of Russia and Hungary: \\ Modern discourse and new actors
}

The authors of the article argue that contemporary cultural policy discourse is in the focus of attention of scientific communities, social and political organizations and government institutions. It represents a sort of symbolic struggle and nominations and has necessitated a new approach to cultural policy structuring. The article shows that this necessity is demonstrated by the development of cooperation between Russia and Hungary in terms of cultural sectors and cultural heritage. Expert communities and non-governmental organizations are becoming significant elements in the structure of cultural policy subjects. The association "For Hungarian-Russian cooperation named after Leo Tolstoy" has become such a key issue.

The authors of this article attempt to highlight the most essential contemporary issues in the sphere of cultural policy in general and in relation of two separate countries - Russia and Hungary - through the scientific project "Hygiene of culture".

Keyword: cultural policy; discourse; subjects of cultural policy; expert-public community

Актуальность проблем культурной политики в современных условиях невызывает сомнения.К началу нового века вопрос о культурной политике оказался в центре внимания научных и общественных дискуссий многих стран, так как проблемы выбора стратегических ориентаций культурной политики могут определить дальнейшую судьбу каждого государства, а результаты проводимой культурной политики воздействуют на сферу культуры, в которой осуществляется производство и воспроизводство ценностных образцов посредством институтов образования, средств массовой коммуникации, творчества и искусства, сохранения и использования наследия.Центральной проблемой при выработке культурной политики и ее реализации являются вопросысоотношения власти и общества, деятельность ее других субъектов, которые актуализируются в настоящее время в различных традиционных и не традиционных организационных формах.

Авторы данной статьи поставили своей целью показать, что несмотря на разность национальных культурных политик в Венгрии, как страны, входящий в Европейский и в силу этого придерживающейся стратегии культурной 
политики Европейского союза, и России, в которой культура впервые возведена в ранг национальных приоритетов ${ }^{1}$, есть то общее, что дает возможность активного плодотворного сотрудничества на международном уровне по воздействию на осознанные и выявленные глубинные проблемы культуры.

В нашей статье мы будем исходит из понимания, что в разных государствах не может быть идентичной культурной политики, типы или модели культурной политики могут совпадать или быть родственными, но конкретное наполнение будет разным; что культурная политика в любой стране, как правило, соответствует ценностно-смысловым основаниям, лежащим в основе доминирующей политико-идеологической системы и представлениям властной элиты о направленности и формах реформирования и модернизации общества; что в культурной политике любого государства присутствуют, как правило, три основные составные части: концептуальная, экономическая и законодательная; что культурная политика - понятие, имеющее широкий спектр значений ибольшое количество интерпретаций данного термина и что культурная политика - явление социально-государственное, а потому конкретно-историческое.

Проблемы культурной политики - это проблемы государственного и общественного статуса культуры, и даже те, кто говорит о слабости или вовсе об отсутствии культурной политикивв современном мире, глубоко заблуждаются. Ошибочность подобных утверждений коренится в существующих в обществе широких расхождениях между представлениями о самоценности культуры как таковой, значении культуры для становления человека, роли и функциях культуры в обществе, наконец, возможностях культуры как фактора, ускоряющего социальные преобразования.

Выбор методов, использованных в работе, обусловлен спецификой предмета и задачами, поставленными авторами статьи, которые обусловиликомплексный междисциплинарный подход.

Междисицплинарность обеспечивалась философским, социологическим, культурологическим, историческим, политологическим, аксиологическим подходами к исследованию проблем культурной политики.

Для раскрытия темы авторы обратились к методам, используемым в научной философской, культурологической, социологической, исторической, аксиологический, политологической литературе, а именно: хронологический метод; ретроспективный метод; историко-сравнительный метод; структурнофункциональный метод; критический метод, социологический метода; метод историко-типологической компаративистики.

1 Распоряжение Правительства Российской Федерации от 29 февраля 2016 года № 326-р «Об утверждении Стратегии государственной культурной политики до 2030 года» http://government.ru/docs/22083/ 
Культурная политика России и Венгрии...

\section{К определению категории «культурная политика»}

Анализ содержания категории «культурная политика» в разные периоды европейской и российской истории показывает, что она представляется явлением историческими претерпевает изменения на временных исторических этапах. Культурная политика всегда соприкасается с конкретными типами культуры, которые не только сменяют друг друга, но могут существовать и синхронно в разных периодах, а также в качестве доминирующего и побочного в рамках одной социокультурной системы [КостинА 2012]. Кроме того, она и вариативна, то есть она строится с учетом исторических традиций территорий и регионов [MAGYARI-BECK 2016; MAGYARI-BECK 2007].

На сегодняшний момент существует большое количество интерпретаций термина «культурная политика» европейскими и российскимиисследователями, которые по-разному трактуют ее смысл и содержание. Обратимся к наиболее характерным.

Французские исследователи в области культуры А. Жерар и Ж. Гентил предложили рассматривать культурную политику как «...систему взаимосвязанных целей, практических задач и средств, выбранных экспертом и направленных на определенную группу в обществе» [GIRARD-GENTIL 1983]. Итальянские исследователи М. ди Анджело и П. Весперини. выделили основные принципы культурной политики:«цели деятельности правительства должны быть ориентированы на интересы региональных органов управления, а также на интересы основных игроков в культурной политике; цели государства должны быть адекватными возможностям субъектов, вовлеченных в процессы культурной политики; реализация культурной политики всегда основывается на материально-техническом и творческом обеспечении функционирования культуры; культурная политика распределяет финансовые, административные, структурные, человеческие и творческие ресурсы; основой культурной политики является планирование - подготовка государства к участию в культурной деятельности и распределении ресурсов» [ANGELO-VESPERINI 1999].

В российской науке также ведутся активные терминологические дискуссии. Ряд ученых акцентирует внимание на социально-ценностных ориентирах культурной политики. Среди представителей такого подхода можно назвать А.Я. Флиера, который говорит о ней как «осмысленной корректировки общего содержания отечественной культуры» [ФлиЕР 2000] и О.Н. Астафьеву, утверждающую, что культурная политика - это «концептуально оформленная совокупность научно обоснованных взглядов и принципов, соответствующих определенным ценностно-смысловым основаниям, целям и приоритетам государства» [АСТАФЬЕВА 2010]. Другие ученые используют комплексный управленческий подход.Так, Л.Е. Востряков утверждает, что система государственной политики «представляет собой целостную совокупность субстанциональных, институциональных и субъектных компонентов воздействия (власть, институты, субъекты)» [ВостРякОВ 2001], а Н.Н. Лавренева считает, что «куль- 
турная политика предполагает планирование, которое представляет собойпроцесс подготовки государства к участию в культурной деятельности, а также в планированиираспределения ресурсов» [ЛАВРиновА 2010]. Е.Е. Беляева кроме государства, расширяет субъектность культурной политики и говорит, что она что «представляет собой воздействие субъекта культурной жизни (государства или личности) на культуру» [БЕЛЯЕВА 2012].

На наш взгляд, можно сказать, что современный дискурс культурной политики представляет собой своеобразное поле символической борьбы и номинаций, поэтому не удивительно, что дискуссии по всему миру в области понимания культурной политики привели к идее, активно разрабатываемой ЮНЕСКО, о необходимости нового подхода к структурированию культурной политики, которая будет соответствовать реалиям устойчивого развития и мирного сосуществования благодаря использованию двойного подхода [ЮНЕСКО 1998]. Вопервых, анализ возможностей государственной поддержки и развития собственно сектора культуры (наследие, творчество, образование, деятельность и учреждения сферы культуры, в частности решение соответствующих задач в области законодательства, финансирования, управления). Во-вторых, определение путей и способов обеспечения культуре принадлежащего ей по праву места в программах всех уровней, ориентированных на развитие и инновацию и, вчастности, на человеческое развитие, образование, научные исследовния коммуникаций, проблемы окружающей среды и социальной сплоченности. Таким образом можно сделать вывод, что конкретизация понятии культурной политики прежде всего зависит от совокупности универсальных общечеловеческих норм и ценностей, национальных традиций. определения участников культурной политики, целей, характера регулирования культурных процессов.

Мы согласны с точкой зрения, высказанной И. Горловой, что методологически правильно рассматривать культурную политику в широком и узком, (прикладном) смыслах. В широком - она учитывает культурные аспекты всех государственных программ экономического, экологического, социального, национального развития. В узком смысле слова, культурная политика предполагает разработку концепции функционирования и дальнейшего прогресса систем образования, науки, культуры, создание в этих целях совокупности норм и принципов, предопределяющих содержание, развитие, распространение культуры, регулирование тенденций прогресса духовно ценностных аспектов общественной жизни [ГОРЛОВА 1988].

В рамках развития сотрудничества между Россией и Венгрией в секторах культуры и культурного наследия демонстрируется понимание необходимости использования новых подходов к культурной политике с ориентацией на определенные показатели, среди которых наиболее значимыми нам представляются следующие: общие цели и принципы культурной политики; культурные меньшинства, группы и сообщества; вопросы языка и языковой политики; социальная сплоченность; культурная политика и СМИ; индустрия культуры; политика занятости и гендерное равенство; основы правового регулирования и финансирование сферы культуры; проблемы социального партнерства и поддержка 
творческой деятельности. Более того, на первый план выступают национальные приоритеты: сохранение культурного наследия, национального богатства, обеспечение равного доступа к культурным ценностям и интеграция в мировой культурный процесс, экономическая рентабельность сферы культуры [SzÜCS 2016].

\section{Экспертно-общественное сообщество в системе субъектов культурной политики}

Как в западной, так и российской литературе различия в осмыслении термина «культурная политика» присутствуют не только в области его применения, но и в определении его субъектов. Большинство исследователей видят в качестве субъекта культурной политики, как отдельную личность, так и организации, работающие в культурной сфере [Жидков 2003]. Другая группа ученых в качестве субъектов культурной политики видит только государство [ФлИЕР 1994]. Авторам статьи разделяют первую точку зрения, считая в сфере культурной политикидолжен действовать принцип позитивной многосубъектности, который сможет привести к кардинальному пересмотру принципов взаимодействия государства с другими субъектами культурной политики.

Основными субъектами культурной политики, кроме государства,необходимо рассматривать учреждения и организации культуры и искусства, которые актуализируются в различных традиционных и не традиционных организационных формах.Важным субъектом реализации культурной политики в условиях рыночных отношений является бизнес - активно действующие хозяйствующие субъекты, в сферах промышленности, торговли, финансов, сервисных услуг.Следующим субъектом культурной политики являются средства массовой информации. Все более важную роль, как субъект культурной политики, стало играть экспертное сообщество, которое мы рассматриваемкак совокупность экспертов в различных областях: непосредственно в сфере культуры и искусства - теоретики и практики культуры, владеющие информацией о тенденциях развития культуры в обществе и ее основных «болевых точках» [Сюч 2016]. Оно способно влиять на принятие решений как со стороны государства, так и со стороны гражданских институтов свободного общества.

Кроме этого важным субъектом культурной политики все чаще стали выступать общественные организации [РЕУт 2016]. Это организации, создающиеся по инициативе отдельных групп людей, которые могут поддерживать различные культурные начинания, создавать независимые фонды, влиять на принятие решений как на уровне муниципальной, региональной, так и федеральной власти.

Общественно-экспертным субъектом культурной политики для России и Венгрии стала Ассоциация «За венгерско-российское сотрудничество имени Льва Николаевича Толстого», которая поставило своей целью изучение актуальных и острых проблем современности в области культуры. Идея была в принципе очень проста, но в то же время чрезвычайно сложная. Проста потому, что цивилизационные проблемы нашей эпохи абсолютно очевидно дошли до угрожающего предела всего ранее достигнутого культурного развития. Сложность же состоит по многим параметрам в ином по сравнению с былыми 
временами характере изменений и вытекающих из них проблем. Это были исходные точки [MAGYARI-BECK 2011].

В процессе дискуссий первых двух конференций, которые проходили шесть лет тому назад в Москве и Будапеште, венгерские и российские ученые самых разных общественно-научных и гуманитарных областей пришли к консенсусу в понимании предложенного термина гигиены культуры [Сюч 2016] и для всех стало очевидным, что инициаторы новой научной дисциплины под гигиеной культуры подразумевают защиту тех культурообразующих компонентов культуры, которые призваны отстаивать гуманную сущность общества, целью которого является обеспечение условий для всестороннего развития человека как свободного и ответственного существа. Пожалуй, мы все видим, что именно эти смыслы и сущности культурного существования человечества подвергаются наибольшей опасности в нашей современной цивилизации.

На данный момент мы имеем очень ценные результаты участвующих в общем исследовании ученых философов, социологов, экономистов, психологов, культурологов, искусствоведов, литературоведов, театроведов, музыковедов, лингвистов, политологов. Объединяет всех нас, во-первых, аксиологический подход к характерным чертам общественных явлений и идейных течений нашей современности, и желание сблизить теорию и практику, то есть теоретические суждения основывать на фактах, и в свою очередь задуматься над возможностью плодотворного воздействия на осознанные и выявленные глубинные проблемы нашей цивилизации. Во-вторых, ответственность именно творческой интеллигенции за судьбу не только своей страны и культуры, но и за судьбу последующих поколений.

Наше общественно-экспертное сообщество поставило своей целью обдумать все те принципиально значимые культурообразующие категории, видоизменения, которые за последние годы означают трансформацию всей системы отношения человека к своему внутреннему и внешнему - социальному миру. Растворение аксиологических норматив и наблюдающееся восновном в западной цивилизации размывание строгих критериев научного подхода к анализу современных явлений наталкивает нас на мысльо необходимости легитимации основных онтологических и гносеологических понятий философского и научного мышления, так как у нас нет других средств для адекватного восприятия мира кроме тех, которые своей адекватностью и с воспроизведенной ими практикой сами себя легитимировали в процессе существования человеческих сообществ.

Без легитимации выработанного тысячилетиями философского понятийного аппарата и - нацеленного на познание истины - философского, художественного и научного /в том числе общественно-научного/ подходов, мы можем утратить основы накопленного знания об окружающей нас природной и социальной действительности, и знания о природе человека, то есть потеряем способность знать и понимать самого себя и окружающий нас мир.

Что может означать анализ любого общественно-культурного процесса с точки зрения гигиены культуры? С теоретической точки зрения в первую оче- 
редь должна быть констатирована проблема, то есть совокупность тех компонентов, которые проявляясь на эмпирически доступном уровне дают возможность определить наличие дисфункции в функционировании данного явления.

Так как процесс анализа дисфункции в большинстве случаев сопровождается столкновением интересов различных социальных групп, ценностных ориентаций или даже культурных парадигм, чрезвычайно важным становится определение критериев оценки, и что требует более абстрактного уровня мысли - определение критерия выборки критериев. Зачастую эта самая отвлеченная стадия процесса уже остается за скобками. При наличии дефиниций выше обозначенных моментов, следует структурирование данной конкретной изучаемой проблемы строго по философским принципам и философскими категориями. Таким образом может быть осуществлен процесс структуризации проблемы, определения ее характера в аксиологическом аспекте.

Относительно анализа различных аспектов культурной политики - мы считаем, что, можно прийти к следующему консенсус в трактовке этого понятия, согласно которой мы понимаем под культурной политикой некий регулятор общественно организующих систем между собой по иерархическому принципу, в которых наблюдаются многослоевые взаимные и взаимно обусловливающие рычаги влияния.

В узком понимании культурная политика может означать одностороннее влияние государства на общественно-культурные процессы, включая задействование неких приоритетных акцентов. В широком смысле культурная политика является сетью вертикально и горизонтально структурированного культурного пространства, в котором существует множество взаимно детерминирующих сил, что не исключает наличия парадигматически определенного главного регулирующего фактора, например, ввиде действующей аксиологической системы. По всей вероятности, сложность настоящей цивилизационной стадии состоитименно в переплетении двух названных структурных особенностей [Сюч 2008].

Мы считаем, что культурная политика проявляется всегда конкретно, в исторически обусловленной конкретной среде определенного общества. Теоретические составляющие понятия культурной политики тем не менее всегда подразумевают общие философские элементы, такие как соотношение индивида и общества, гражданского общества и политикума, прав человека на самоопределение и право общества на защиту своих культурных основ и уставов, соотношение прав и обязанностей, вопросы уровня стойкости или же гибкость, вариативность границ, соотношения относительности и абсолютности в менталитете населения и практики государственных структур, историческая необходимость в упразднении или же усилении государственного контроля над общественными процессами и много иных аспектов, которые могут характеризовать теоретические рамки конкретности подходов.

В культурной политике непременно присутствует наличие совпадения или же расхождение интересов структурирующих элементов общества, а также столкновение определенных, обязательно не совпадающих ценностных си- 
стем, которые непременно будут отстаивать определяющие собственные ценностные ориентации интересы. И, конечно же в конечном счете мы обязательно придем к человекообразующим принципам, таким как свобода или степень компромиссоспособности индивида, которые закономерным образом закладывают кирпичики разногласия в общий фундамент конструкции, называемой обществом [PIGROV 2006; ТАНАTOBA 2008].

Ценностный подход позволяет объединить - в силу природы общезначимых для данной цивилизации ценностей - основные аспекты культуры в их единстве и многообразии: в общезначимом мировоззренческом смысле; в процессе человеческой, прежде всего творческой художественной деятельности и сопряженных с ней производств и продуктов (результатов) [SZUCS-YUDINA 2017). Как справедливо подчеркивает профессор А.В. Шестопал, «общества без идеологии не бывает: там, где нравственные ценности объявляются необязательными, их место занимают более примитивные ценности: «быстрого гедонизма», безграничного потребления, «аморализма» и т.д. [ШЕСтоПАЛ 2015].

Мы закономерно приходим к необходимости четкого определения соотношения критериев общего блага и самореализации личности. Ведь согласимся, неразрешенные проблемы практики культурной политики обусловлены именно не разработанностью консенсуса по поводу этих критериев. Тем не менее, руководствуясь вышеназванными общими критериями необходимости определения правильного соотношения общего блага и свободой самореализации личности, при принятии конкретных решений, влияющих на состояние общества, пожалуй, можно предположить, что соотношение этих двух компонентов есть возможность, и даже иногда необходимость сознательно скорректировать и направить на определенные траектории согласно конкретной ситуации, которую переживает данное общество в данный временной отрезок.

Таким образом, некое сознательное смещение акцентов на создание условий самореализации личности и ослабление государственного, властного, или же ведомственного контроля может иметь место при восходящей линии развития данного общества, критерии чего тоже пока не определены, но во всяком случае могут характеризоваться относительной стабильностью политико-экономической ситуации, при наличии относительного общего консенсуса между властью и народом, при преобладании созидательных процессов направленных на укрепление благосостояния обществаи на наименьшую внешнюю угрозу.

Степень благосостояния общества - в нашей культурной парадигме и по определению гигиены культуры, определяется степенью гуманности системы регуляции и саморегуляции общественных отношений. Культурная политика всегда должна руководствоваться целями, поддерживания этих позитивных процессов.

Естественным образом, время от времени каждое общество переживает стадии дестабильности, видоизменения и даже смены парадигм. Эти процессы могут быть длительными или же происходить турбулентно, зачастую в форме острого противостояния и с непредсказуемыми последствиями, которые по опыту истории могут носить разрушительный характер. 
Что касается изучения истории культурной политики последнего столетия конкретной страны, с полной уверенностью можем сказать, что при описании отдельных стадий применяется исключительно принцип периодизации по историческим эпохам. В зависимости от точки зрения автора, которая зачастую зависит от общественно-политической парадигмы актуальной стадии истории страны, дается та или иная оценка конкретных процессов. В случае смены исторической парадигмы, меняется и система аксиологической координации.

На примере Венгрии мы можем привести три исторических периода относительно описания истории культурной политики [ФОНАИ 2005; ДРАБАНЦФОНАИ 2005). Каждый из перечисленных этапов соответствует конкретной исторической парадигме, а система оценочных координат видоизменяется по ценностям того исторического периода, в котором делается оценка. Соответственно, в описании периодов культурной политики Венгрии последнего столетия различается период между двумя мировыми войнами, включительно 1941-44 годы и берется временной рубеж 1920-1944-х годов; второй период 1944-1948-е годы - касается т.н. коалиционного периода истории страны, когда еще не наступил этап социализма; третий период соответственно касается 1948-1990-х годов, периода социализма.

В качестве отдельного периода культурной политики с 1990-х годов до наших дней, систематического описания процессов не произошло. Авторы ограничиваются констатацией этого факта ссылаясь на отсутствие необходимой исторической перспективы и на множество противоречивых процессов, объясняемых переходным этапом общественных и политических изменений. Мы уверены в общем принципиальном согласии в том, что настоящая стадия нашей цивилицазии пришла к очень ответственному моменту выбора дальнейшего пути, который определит на долгие годы, и может десятилетия, судьбу наших культур. В этом ответственном процессе имеет огромную роль культурная политика, которая может обозначить вектор дальнейшего направления движения всех общественных процессов и тем самым всего общества в целом.

Приоритеты современной культурной политики не могут выстраиваться без учета влияния глобализационных процессов, задающих культурно-цивилизационному развитию сильную нелинейность. Нелинейность проявляется на разных социокультурных уровнях: - фактически, человек любой культуры сегодня вписан в “сетку" сталкивающихся, переплетающихся, накладывающихся друг на друга информационно-коммуникативных процессов.

Провозглашение ценностно ориентированного подхода не должно бытьформальным, декларативным, бессодержательным.

Мы уверены, что анализ культурной политики различных государств может стать фундаментом для поиска перспективных моделей их развития в современных условиях. 


\section{Библиография}

АСТАФЬЕВА 2010: Астафьева, О.Н., Культурная политика: теоретическое понятие и управленческая деятельность: лекции.Москва: Издательство РАГС.

БЕЛЯЕВА 2012: Беляева, Е.Е., Культурная интеграция как основная стратегия культурной политики Европейского союза: Монография: Москва: МПГУ.

ВостРякОв 2001: Востряков, Л.Е., Государственная культурная политика современной России: региональное измерение: дис. ... докт. полит. наук. Москва.

Всемирный доклад по культуре. 2011: 1998 год. Культура, творчество и рынок Текст. Москва: Ладомир: Юнеско.

ГоРлОВА 1998: Горлова, И.И., Культурная политика в современной России: региональный аспект. Краснодар.

ДРАБАНЦ-ФОНАИ 2005: Драбанц, Р., Фонаи, М., История венгерской культурной политики: 1920-1990. Издательство Чоконаи.

Жидков-Соколов 2003: Жидков, В.С., Соколов К.Б., Искусство и картина мира. СПб.: Алетейя.

КостинА 2012: Ответственность государства перед культурой. Социальные интересы и цели культурной политики. Культура и гигиена. Гуманизм как потребность. Материалы круглого стола «Гигиена культуры-культурологический обзор», организованного Ассоциацией «За венгерско-российское сотрудничество им. Льва Николаевича Толстого» 30 мая-1 июня 2012 год. Ответственные редакторы: д-р Иштван Мадьяри-Бек и д-р Ольга Сюч. Ассоциация им. Л.Н. Толстого-Издательство Каирос, Будапешт.

ЛАВРИнОВА 2010: Лавринова, Н.Н., Сущность культурной политики. Электронное научное издание «Аналитика культурологии». Выпуск 2 (17), 2010.

РЕУт 2016: Реут, Д.В., Университет гигиены культуры. Опыт образовательной инженерии. // Гигиена культуры: Общий концепт и виды социальных болезней. Российский государственный социальный университет. Москва, Ru SCIence. Портал российской науки.

Сюч 2008: Сюч, O., Gazdaság és Müvészet (elméleti és pragmatikus összefüggések). (Экономика и искусство. Теоретические и прагматические аспекты.) // Tudomány határok nélkül. Tudományos Mozaik, 5. kötet, Második rész. Tomori Pál Főiskola.

Сюч 2016: Сюч, О., Закономерность возникновения и задачи науки Гигиены культуры // Гигиена культуры: Общий концепт и виды социальных болезней. Российский государственный социальный университет. Москва, Ru SCIence. Портал российской науки.

ТАНАТОВА 2008: Танатова, К.Д., Общество, культура, нравственность: концепты ХХІ века. В сборнике: Научные школы РГСУ: основные концепты и перспективы развития Москва, 177-187.

ФлИЕР 1994: Флиер, А.Я., О новой культурной политике России Текст. / А.Я.Флиер // Общественные науки и современность. 1994/5: 14-25.

ФлИЕР 2000: Флиер, А.Я., Культурно-политологическое исследование: О новой культ.политике России // Культурология для культурологов, Москва: 407-424.

ФОНАИ 2005: Фонаи, М., История венгерской культурной политики. Издательство Чоконаи.

ШЕСтоПАЛ 2015: Шестопал, А.Я., Открывая ХХ Шишкинские чтения: ключевые вопросы науки и этики в современном мире. Вестник МГИМО-Университета. 2015/42(3):256-257.

Angelo-Vesperini 1999: D’Angelo, M., Vesperini, P., Cultural Policies in Europe: Method and Practice of Evaluation. Council of Europe Publishing. 
GIRARD-GENTIL 1983: A. Girard, G. Gentil, Cultural Development: experiences and policies. Paris: UNESCO.

https://www.litres.ru/e-e-belyaeva/kulturnaya-integraciya-kak-osnovnaya-strategiyakulturnoy-politiki-evropeyskogo-souza/ (дата доступа 03.10.2018)

MAGYARI-BECK 2007: Magyari-Beck, I., Mitől szenved az euroatlanti civilizáció? (Om чего страдает евроатлантическая циивилизациия?) Valóság, 2007/6.

MAGYARI-BECK 2011: Magyari-Beck, I., A világ(osság) mint a kis népek köztársasága. (Brightness coming from the republic of small nations). Valóság, 2011/8.

MAGYARI-BECK 2016: Magyari-Beck, I., Culture "B" and its holders. // Hygiene of Culture: Concept and Types of Social Diseases. Russian State Social University. Ru SCIence, Moscow.

PIGROV 2017: Lovers of philosophy and professionals: alternative horizons XXI V. // Alternative education in search of quality: materials of conferences on alternative education. St. Petersburg, 2006.

SzÜCS 2016: The Low of Developement and Objektives of Science the Culture Hygiene.// Hygiene of Culture: Concept and Types of Social Diseases. Russian State Social University. Ru SCIence, Moscow.

SZUCS-YUDINA 2017: Szucs, О., Юдина T.H., Significance of the new trends in contemporary art and the transformation of culture institutions.B сборнике: Economic and Social Development Book of Proceedings. Varazdin Development and Entrepreneurship Agency; Russian State Social University.

URL: http://analiculturolog.ru/component/k2/item/229-article_41.html (дата доступа 03.10.2018).

Ольга Сюч University of Debrecen Debrecen, Hungary szucsolga3@gmail.com

Татьяна ЮдинА Russian State Social University Moscow, Russia ioudinatn@mail.ru 